NASA/CR—2003-211828

Effect of Velocity in Icing Scaling Tests

David N. Anderson

Ohio Aerospace Institute, Brook Park, Ohio 
Since its founding, NASA has been dedicated to the advancement of aeronautics and space science. The NASA Scientific and Technical Information (STI) Program Office plays a key part in helping NASA maintain this important role.

The NASA STI Program Office is operated by Langley Research Center, the Lead Center for NASA's scientific and technical information. The NASA STI Program Office provides access to the NASA STI Database, the largest collection of aeronautical and space science STI in the world. The Program Office is also NASA's institutional mechanism for disseminating the results of its research and development activities. These results are published by NASA in the NASA STI Report Series, which includes the following report types:

- $\quad$ TECHNICAL PUBLICATION. Reports of completed research or a major significant phase of research that present the results of NASA programs and include extensive data or theoretical analysis. Includes compilations of significant scientific and technical data and information deemed to be of continuing reference value. NASA's counterpart of peerreviewed formal professional papers but has less stringent limitations on manuscript length and extent of graphic presentations.

- TECHNICAL MEMORANDUM. Scientific and technical findings that are preliminary or of specialized interest, e.g., quick release reports, working papers, and bibliographies that contain minimal annotation. Does not contain extensive analysis.

- CONTRACTOR REPORT. Scientific and technical findings by NASA-sponsored contractors and grantees.
- CONFERENCE PUBLICATION. Collected papers from scientific and technical conferences, symposia, seminars, or other meetings sponsored or cosponsored by NASA.

- SPECIAL PUBLICATION. Scientific, technical, or historical information from NASA programs, projects, and missions, often concerned with subjects having substantial public interest.

- TECHNICAL TRANSLATION. Englishlanguage translations of foreign scientific and technical material pertinent to NASA's mission.

Specialized services that complement the STI Program Office's diverse offerings include creating custom thesauri, building customized data bases, organizing and publishing research results ... even providing videos.

For more information about the NASA STI Program Office, see the following:

- Access the NASA STI Program Home Page at http://www.sti.nasa.gov

- E-mail your question via the Internet to help@sti.nasa.gov

- Fax your question to the NASA Access Help Desk at 301-621-0134

- Telephone the NASA Access Help Desk at 301-621-0390

- Write to:

NASA Access Help Desk

NASA Center for AeroSpace Information 7121 Standard Drive

Hanover, MD 21076 
NASA/CR-2003-211828

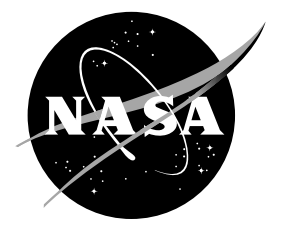

\section{Effect of Velocity in Icing Scaling Tests}

David N. Anderson

Ohio Aerospace Institute, Brook Park, Ohio

Prepared for the

38th Aerospace Sciences Meeting and Exhibit

sponsored by the American Institute of Aeronautics and Astronautics

Reno, Nevada, January 10-13, 2000

Prepared under Cooperative Agreement NCC3-884

National Aeronautics and

Space Administration

Glenn Research Center 


\section{Acknowledgments}

This work was supported by the NASA Glenn Research Center Icing Branch under a grant to the Ohio Aerospace Institute. Assistance in planning and executing the tests was provided by Dr. Gary Ruff, Drexel University and by Dr. Judy van Zante and Howard Broughton of NASA Glenn.

The cooperation and assistance of Bill Sexton and the entire IRT staff to install and test the models were, as always, invaluable.

This report contains preliminary

findings, subject to revision as analysis proceeds.

The Aerospace Propulsion and Power Program at NASA Glenn Research Center sponsored this work.

Available from

NASA Center for Aerospace Information 7121 Standard Drive

Hanover, MD 21076
National Technical Information Service 5285 Port Royal Road Springfield, VA 22100 


\title{
EFFECT OF VELOCITY IN ICING SCALING TESTS
}

\author{
David N. Anderson* \\ Ohio Aerospace Institute \\ Brook Park, Ohio 44142
}

\begin{abstract}
$\underline{\text { Abstract }}$
This paper presents additional results of a study first published in 1999 to determine the effect of scale velocity on scaled icing test results. Reference tests were made with a 53.3-cm-chord NACA 0012 airfoil model in the NASA Glenn Icing Research Tunnel at an airspeed of $67 \mathrm{~m} / \mathrm{s}$, an $M V D$ of $40 \mu \mathrm{m}$, and an $L W C$ of $0.6 \mathrm{~g} / \mathrm{m}^{3}$. Temperature was varied to provide nominal freezing fractions of $0.8,0.6$ and 0.5 . Scale tests used both 35.6- and 27.7-cm-chord 0012 models for $2 / 3$ - and $1 / 2$-size scaling. Scale test conditions were found using the modified Ruff (AEDC) scaling method with the scale velocity determined in five ways. Four of the scale velocities were found by matching the scale and reference values of water-film thickness, velocity, Weber number and Reynolds number. The fifth scale velocity was simply the average of those found by matching the Weber and Reynolds numbers. The resulting scale velocities ranged from 85 to $220 \%$ of the reference velocity. For a freezing fraction of 0.8 , the value of the scale velocity had no effect on how well the scale ice shape simulated the reference shape. For nominal freezing fractions of 0.5 and 0.6 , the best simulation of the reference shape was achieved when the scale velocity was the average of the constantWeber-number and the constant-Reynolds-number velocities.
\end{abstract}

\section{Nomenclature}

$A_{c} \quad$ Accumulation parameter, dimensionless

$b \quad$ Relative heat factor, dimensionless

c Model chord, $m$

$c_{p, w s} \quad$ Specific heat of water at the surface temperature, cal $/ \mathrm{g} \mathrm{K}$

$h_{\text {flum }} \quad$ Water-film thickness at leading edge, $\mathrm{m}$

$K_{0} \quad$ Modified inertia parameter, dimensionless

LWC Cloud liquid-water content, $\mathrm{g} / \mathrm{m}^{3}$

$M \quad$ Mach number, dimensionless

MVD Water droplet median volume diameter, $\mu \mathrm{m}$

*Senior Research Associate, Member AIAA $n \quad$ Freezing fraction, dimensionless

$r_{l e} \quad$ Leading-edge radius of airfoil, $\mathrm{m}$

Re Reynolds number of model, dimensionless

$R e_{\delta} \quad$ Reynolds number of water droplet, dimensionless

$t_{s t} \quad$ Static temperature, ${ }^{\circ} \mathrm{C}$

$t_{\text {tot }} \quad$ Total temperature, ${ }^{\circ} \mathrm{C}$

$V \quad$ Air velocity, $\mathrm{m} / \mathrm{s}$

We Weber number based on droplet size and water properties, dimensionless

$\phi \quad$ Droplet energy transfer terms in energy balance, ${ }^{\circ} \mathrm{C}$

$\Lambda_{f} \quad$ Latent heat of freezing, cal $/ \mathrm{g}$

$\rho_{l} \quad$ Ice density, $\mathrm{g} / \mathrm{m}^{3}$

$\theta \quad$ Air energy transfer terms in energy balance, ${ }^{\circ} \mathrm{C}$

$\tau \quad$ Accretion time, $\min$

\section{Introduction}

This paper presents the results of a continuation of a 1998 study published in $1999^{1}$ to determine the effect of scale velocity on scaled ice shapes.

To minimize test-section blockage in icing tunnels, it is often necessary to test reduced-size models. Scaling methods are thus required to determine scaled test conditions that will simulate the full-scale icing encounter and produce the same non-dimensional ice shape. Similarity parameters have been identified which best describe the important phenomena of icing physics. Scaling methods ${ }^{2,3}$ have been developed by selecting those similarity parameters that appear to have the most influence on ice accretion, and requiring that the parameters have the same value for both scale and reference tests. The phenomena important to icing include the flowfield approaching and around the model, the droplet trajectories, the quantity of ice accumulation, the surface heat balance and, possibly, phenomena related to the dynamics of surface water on the model. For rime ice, because water freezes on impact, only the first three of these phenomena affect the ice shape.

The flowfield can be simulated by matching scale and reference values of $R e$ and $M$, by using a model whose 
non-dimensional coordinates are the same as the fullscale (reference) article and by setting the scale angle of attack equal to the reference. For icing encounters, the speeds involved are usually low such that $M$ should have little effect and is neglected. In the past, $R e$ has usually been ignored by arguing that any ice accretion will trip the boundary layer and the flow will then be independent of $R e$. However, Bilanin ${ }^{4}$ advocated including $R e$ in icing scaling analyses, and recently, the study of reference 1 used $R e$ as an optional scaling parameter.

Similarity of droplet trajectories and, therefore, droplet collection efficiencies, can be obtained by matching the modified inertia parameter, $K_{0}$, of Langmuir and Blodgett. $^{5}$

Similarity of ice accumulation results from a match of the accumulation parameter, $A_{c}$ :

$$
A_{c}=\frac{L W C V \tau}{2 r_{l e} \rho_{i}}
$$

Here, $r_{l e}$ is the leading-edge radius of the model. The length scale used to compute the values of all of the similarity parameters in this study was twice the leading-edge radius. For the NACA 0012, the leadingedge radius is $1.58 \%$ of the chord.

The energy balance at the surface is based on the work of Messinger. ${ }^{6}$ The energy balance can be written in the form,

$$
n=\frac{c_{p, w s}}{\Lambda_{f}}\left(\phi+\frac{\theta}{b}\right)
$$

where $n$ is the freezing fraction; $\phi$, the water energy transfer parameter; $\theta$, the air energy transfer parameter; and $b$, the relative heat factor, defined by Tribus, et al. ${ }^{7}$ Equation (2) provides additional similarity parameters for scaling, but only three of the four are independent. For this study, only $n, \phi$ and $\theta$ will be considered.

Finally, some understanding of surface dynamics can provide still more similarity parameters. Two of these are the Weber number, We, and the non-dimensional water-film thickness, $h_{\text {film }} / c$. $\mathrm{Kind}^{8}$ has also identified parameters, but for the present study, these will not be considered. For this investigation, We was based on the droplet size. An experimental correlation for waterfilm thickness was given by Feo and Urdiales: ${ }^{9}$

$$
\frac{h_{f i l m}}{c} \propto L W C^{1 / 2}(R e)^{-1 / 4}\left(R e_{\delta}\right)^{15 / 4}(W e)^{-9 / 4}
$$

This correlation was based on tests of the effect of rain on aircraft performance; thus, the water droplets were at least an order of magnitude larger than those experienced in conditions described by FAA FAR 25 Appendix C. The $L W C$ 's in the Feo and Urdiales study were also higher than those of interest here. Consequently, equation (3) may not be applicable to Appendix $\mathrm{C}$ icing. Because there is no other data relating water film thickness to icing parameters, however, equation (3) will be used with reservations.

From the above discussion, then, eight scaling parameters can be considered: $R e, K_{0}, A_{c}, n, \phi, \theta$, We and $h_{\text {film }} / c$. After the reference conditions for the test to be simulated have been selected along with the scale-toreference size ratio, there are five test conditions for the scale test that need to be established: the static temperature, velocity, cloud droplet size, cloud liquidwater content and the icing time. In icing tunnels with altitude capability, the scale test-section pressure is a sixth condition that must be determined. The present work was performed in a sea-level tunnel, so pressure was established by ambient conditions.

Ruff $^{3}$ performed tests in the AEDC R-1D icing tunnel to evaluate the importance of the parameters, $K_{0}, A_{c}, n$, $\phi$, and $\theta$ to scaling. He found that the scaled ice shapes agreed best with reference shapes when all five parameters were matched to the reference values. This approach to scaling is known as the Ruff (or AEDC) Method. Because the R-1D allows altitude simulation, Ruff's work included the calculation of the scale testsection pressure in addition to temperature, $M V D, L W C$ and time. The scale velocity is selected arbitrarily in the Ruff Method. The Ruff Method has also been used in sea-level tunnels in a modified form in which $\theta$ is ignored and just the remaining four parameters are matched. Scale velocity is chosen by the user for this modified Ruff Method, as well.

In Ruff's experiments, the scale velocity was often simply equated with the reference value. This is a practical approach, and it coincidentally insures that $\theta$, $b$ and $M$ will match between the scale and reference situation. Although some more recent studies have been done with velocity selected by matching $W e^{10,11}$, until the study of reference (1), the choice of scale velocity and its effect on scaling results has not received much attention.

Reference (1) reported a series of $1 / 2$-size scaling tests performed in the NASA Glenn Icing Research Tunnel. Five sets of reference conditions were tested with the full-size model (53.3-cm-chord NACA 0012 airfoil). Tests with a $26.7-\mathrm{cm}$-chord 0012 were made with scale conditions determined by the modified Ruff method. 
(Because the IRT is a sea-level tunnel, the parameter $\theta$ was ignored.) Five possible scale velocities were determined for each reference case. These were found by matching either $h_{f i l m} / c$, velocity, $W e, R e$, or the average of velocities found by matching $W e$ and $R e$. This average- $V$ method has no physical basis, but it was used to assist in spotting possible trends with velocity. The matching of $h_{\text {film }} / c$ was referred to as the Feo method; it produced a scale velocity of about $85 \%$ of the reference. The scale velocity for the constant-We approach was about $130 \%$, for the average- $V$, about $175 \%$, and for the constant-Re, about $220 \%$ of the reference. The scale velocities for the constant-Re method in some cases were higher than the tunnel capabilities permitted and, in others, produced total temperatures above freezing. Even the average- $V$ method sometimes gave total temperatures above freezing. Thus, not all of the five sets of reference cases could be tested with all scale velocities.

The study of reference (1) found that for tests with freezing fractions higher than 0.8 , including some tests with rime ice, scale velocity had little effect on scaled shapes. For a freezing fraction of about 0.5 , there was better agreement between the scale and reference ice shapes as the scale velocity increased, as long as the scale total temperature was below about $-2^{\circ} \mathrm{C}$. At a freezing fraction of 0.3 a clear trend could not be established since even the average-velocity method gave a total temperature above $0{ }^{\circ} \mathrm{C}$.

Additional tests were performed in 1999 to obtain supplementary data and to investigate some of the questions raised by the 1998 study reported in reference (1). Because that previous study ignored the scaling parameter $\theta$, the present work included some tests to evaluate whether results would be different if $\theta$ were used instead of $\phi$ as part of the system of equations to determine scale conditions. While constant $\phi$ results in simpler equations to solve, constant $\theta$ produces a lower scale total temperature. In addition to the $1 / 2$-scale results, a few sets of ice shapes will be shown for scaling from a chord of $53.3 \mathrm{~cm}$ to $35.6 \mathrm{~cm}(2 / 3$ scale). NACA 0012 models were again tested in the NASA Glenn Icing Research Tunnel at $0^{\circ}$ angle of attack. Along with results from the 1999 tests, this paper will also present additional results from 1998.

\section{$\underline{\text { Reference Conditions }}$}

All reference tests were made with $53.3-\mathrm{cm}$-chord models. The nominal test conditions are shown in table I. Three reference cases, designated 110, 111 and 112 , were taken from the study of reference (1). Each case has a different freezing fraction due to the different
Table I. Reference Test Conditions

Reference Model, 53.3-cm-Chord NACA 0012

Reference Airspeed, $67 \mathrm{~m} / \mathrm{s}$

Reference $M V D, 40 \mu \mathrm{m}$

Reference $L W C, 0.6 \mathrm{~g} / \mathrm{m}^{3}$

Reference Spray Time, $11.2 \mathrm{~min}$

$\begin{array}{cccc} & t_{s t}, & t_{\text {tot }}, & \\ \text { Case } & { }^{\circ} \mathrm{C} & { }^{\circ} \mathrm{C} & n \\ 110 & -13.9 & -11.7 & 0.8 \\ 111 & -11.1 & -8.9 & 0.7 \\ 112 & -8.4 & -6.1 & 0.5\end{array}$

temperature. The airspeed, droplet size, liquid-water content and spray time were the same for all cases. The reference shapes from reference (1) were used again for this study. Actual recorded test conditions for both reference and scale tests will be given with the ice shapes. The values of some of the scaling parameters to be given in this paper may differ from those previously reported due to changes in the calculation routines used.

\section{Test Description}

\section{NASA Glenn Icing Research Tunnel}

The facility and hardware used are shown in figure 1. Figure 1(a) is a plan view of the NASA Glenn Icing Research Tunnel (IRT). ${ }^{12,13}$ The IRT has a test section width of $2.7 \mathrm{~m}$ and a height of $1.8 \mathrm{~m}$. It has a refrigeration system that allows accurate control of the test-section temperature from -40 to $4{ }^{\circ} \mathrm{C}$. A water spray system with ten spray bars simulates the conditions in a natural icing cloud. The test-section cloud droplet size, $M V D$, and liquid-water content, $L W C$, depend on spray-bar air and water pressures. The relationships among these pressures, the tunnel airspeed and the cloud properties are established periodically by a series of tunnel calibration tests. ${ }^{14}$ The cloud has been calibrated over a range of test-section airspeeds from 22 to $156 \mathrm{~m} / \mathrm{s}$ and droplet median volume diameters from 14 to $50 \mu \mathrm{m}$. Two sets of spray nozzles, the Mod-1 and Standard, are used to provide different ranges of liquid-water content. Depending on the nozzle set, the airspeed and the droplet diameter, the test-section liquid-water content can be controlled from less than 0.2 to over $5 \mathrm{~g} / \mathrm{m}^{3}$. The Standard nozzles were used for the 1999 tests, while the Mod-1's were used in 1998.

The IRT spray system includes a water valve at each nozzle, and water is recirculated prior to the start of the spray. Spray-bar air and water pressures can thus be 
established and stabilized before spray is admitted to the tunnel. This feature virtually eliminates startup transients that were present previously in the IRT.

A cold room is mounted on the side of the tunnel with access through the diffuser as well as from the outside. The coldroom temperature can be controlled to permit ice studies off line. A threedimensional scanner in

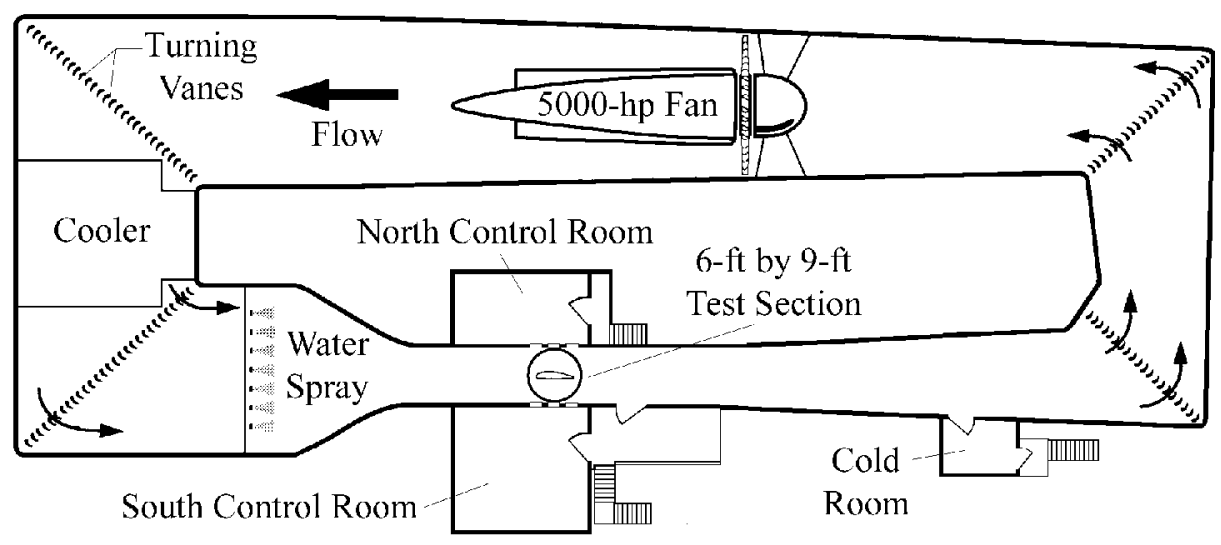
the cold room is available for digitally recording the ice-shape coordinates of ice accretions. Although the ice produced in this study was scanned, the shapes to be presented here were obtained from two-dimensional hand tracings of the ice cross section.

\section{$\underline{\text { Test Models and Procedures }}$}

The same NACA 0012 airfoil models were used in both the 1998 and 1999 studies. Chords were $53.3 \mathrm{~cm}$ (reference model), $35.6 \mathrm{~cm}$ and $26.7 \mathrm{~cm}$. Each was mounted vertically, at $0^{\circ}$ angle of attack, in the center of the IRT test section. The models were machined from solid aluminum. All had a span of $61 \mathrm{~cm}$ and were placed between end plates as shown in figure 1(b). The models' mid spans were located on the tunnel centerline (midway between floor and ceiling of the test section). The five horizontal lines marked around the leading edge of the model indicate the mid-span and positions 2.5 and $5 \mathrm{~cm}$ above and below mid-span. Ice shapes were recorded only at the mid-span and $5-\mathrm{cm}$ above locations for the 1999 study and at mid-span, $\pm 2.5 \mathrm{~cm}$ and $5 \mathrm{~cm}$ above mid-span for the 1998 tests. In this paper, only the mid-span shapes will be shown.

The test temperature and airspeed were first established, then the spray-bar air and water pressures were set and stabilized. To initiate the spray, the water valves were opened and the spray timer started. At the completion of the desired time, the spray was turned off and the tunnel fan stopped. For the 1999 tests, the model was removed from its stand and carried to the cold room where the surface coordinates were recorded with the 3D laser scanner. After scanning, a thin heated aluminum plate was used to melt horizontal slots through the accreted ice at specific span-wise locations. The ice shapes were traced by hand onto cardboard templates inserted into these slots in the ice. Two 
Following the test, the ice-shape tracings were digitized to provide a permanent record of each shape. The ice shapes to be shown in this report were plotted from these 2-D digital records.

\section{Average Test Conditions}

Tunnel and cloud conditions were recorded at $1-\mathrm{sec}$ intervals for tests with the 26.7- and 35.6-cm-chord models and at 2-sec intervals for the $53.3-\mathrm{cm}$-chord model. Averages of the 1- or 2-sec readings over the spray period were made for each instrument used. The test-section total temperature at any moment was the average of the readings of eleven type-T thermocouples located on the turning vanes upstream of the spray bars. The test-section velocity was found from the averages of the pressures from two pitot-static probes on opposite walls at the entrance to the test section. The $M V D$ and $L W C$ were calculated from the averages of the ten spray-bar air pressures and water-air differential pressures. The conditions reported in this paper are these instrument averages averaged over time. These conditions will be tabulated as part of the ice-shape comparisons in figures 3 to 6 . The scaling parameters shown in these figures have been computed from these average test conditions.

\section{Uncertainty}

Estimates of the uncertainty in the reported average conditions were made by considering fluctuations of the values with time, possible instrument errors including calibration, uncertainties in tunnel calibration of $M V D$ and $L W C$, and differences in measurements from one location to another in the test section. From this analysis for the conditions of the tests reported here total temperatures are probably known to within $\pm 1.5^{\circ} \mathrm{C}$, velocity, $\pm 2.5 \%, M V D, \pm 11 \%$ and $L W C$, $\pm 12 \%$. There is no absolute standard for drop-sizing instruments; therefore, the use of different instruments or operators to measure the clouds tested could produce $M V D$ 's outside this range of uncertainty.

The uncertainties in the scaling parameters were determined from the above test-condition uncertainties. $K_{0}$ is thus estimated to be known within about $\pm 22 \%$, $A_{c} \pm 12 \%, n \pm 10 \%, b \pm 12 \%, \phi \pm 3 \%, \theta \pm 3 \%, R e \pm$ $3 \%, W e \pm 12 \%$ and $M \pm 3 \%$. At this time, the effect on the ice shape of varying scaling parameters by these magnitudes is unknown.

\section{$\underline{\text { Results and Discussion }}$}

$\underline{\text { Considerations of Nozzle Type and Span-wise Position }}$

Some of the ice-shape comparisons to be presented will be made between tests made in 1998 and 1999 using

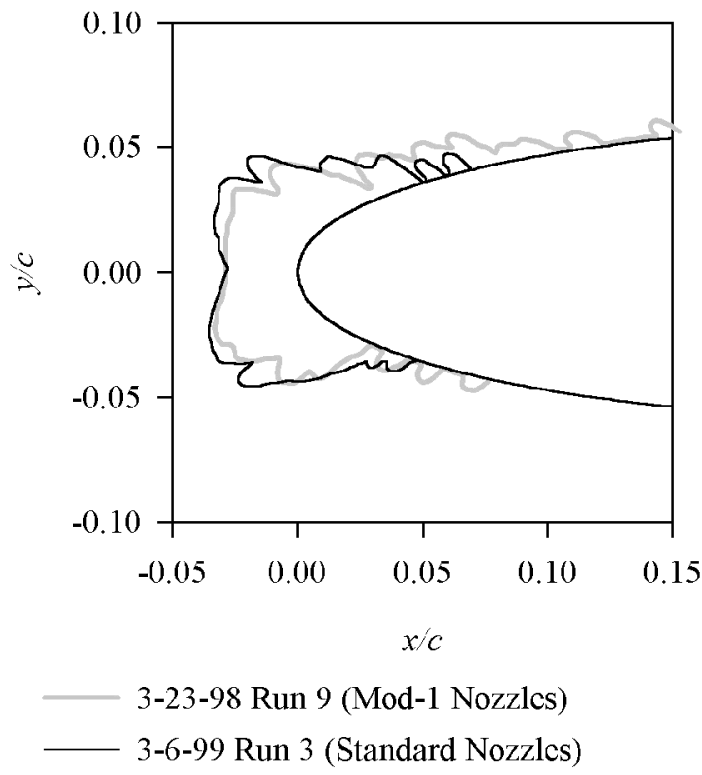

Figure 2. Comparison of Results From Tests Using Mod-1 and Standard Nozzles. $c, 26.7 \mathrm{~cm} ; t_{s t}$, $-11^{\circ} \mathrm{C} ; V, 88 \mathrm{~m} / \mathrm{s} ; M V D, 24 \mu \mathrm{m} ; L W C, 0.77$ $\mathrm{g} / \mathrm{m}^{3} ; \tau, 3.7 \mathrm{~min}$.

different nozzle sets. To determine consistency between the results for the two types of nozzles, some tests from 1998 were repeated in 1999. Figure 2 compares the results of a scale test from 1998 using the Mod-1 nozzle set with one run in 1999 at the same conditions but with the Standard nozzles. The two ice accretions displayed only minor differences, and these were typical of the shape variations observed when icing sprays are repeated with the same nozzle. The quality of the shape agreement indicated by figure 2 was observed with several other repeat tests that were made. It was concluded that the 1998 and 1999 results can be directly compared.

Reference (1) showed comparisons of ice shapes traced at different span-wise locations from $2.5 \mathrm{~cm}$ below the mid span to $5 \mathrm{~cm}$ above. No significant variations in ice shape were seen. Similarly, in the tests made in 1999, no meaningful differences between the mid-span shapes and those recorded $5 \mathrm{~cm}$ above mid span were observed. Thus, small errors in locating the span-wise positions for the tracings should have had no effect on ice shape.

\section{$\underline{1 / 2 \text {-Size Scaling with Rime Ice }}$}

When there is sufficient convective heat transfer to absorb all the latent heat released, water freezes immediately on impact to form rime ice. Consequently, a description of the heat balance at the surface is unnecessary, and, with no liquid water on the ice, 
dynamics of a liquid surface are irrelevant. For this situation, only the reference accumulation and inertia parameters, $A_{c}$ and $K_{0}$, have to be matched by the scale test, and any method to choose scale velocity should be equally valid. Reference (1) presented results of scaling to $1 / 2$ size with scale velocities using the Feo, constant-velocity, constant-We and average-velocity methods. The four scale tests produced evidence that rime shapes should not change with scale velocity. However, some rime ice shapes in reference (1) were smaller than expected due to an inconsistency in the tunnel $L W C$ calibration over the range of velocities tested. That calibration has since been revised, and the 1999 tests used the latest IRT calibration. No additional rime results will be shown here.

$\underline{1 / 2-S i z e}$ Scaling at Nominal Freezing Fraction of 0.8 (fig. 3)

The ice shapes are shown in the plots with nondimensional coordinates. The reference shape is drawn with a gray line and is repeated for comparison with the scaled shapes in each portion of the figure. Figure 3(a) shows the scaled shape which resulted from testing with the Feo scale velocity; figure 3(b), the constantvelocity; figure 3(c), the constant-We; and figure 3(d), the average of the constant-We and constant-Re velocities. The ice shapes shown in figures 3(a), (b) and (c) have already been reported in reference (1). The average-velocity result in figure $3(\mathrm{~d})$ adds a higher velocity scale test than what was given in reference (1). The first column of numbers below the plots of ice shapes in figure 3(a) gives the reference test conditions and scaling parameters. The scale test conditions are listed under the corresponding portion of the figure.

There are usually three attributes of an ice shape that need to be evaluated when judging the effectiveness of scaling. They are the quantity of ice accreted, the limits of accretion, and the size and location of significant features such as horns. The scale velocity had little effect on any of these characteristics of the scale ice shape at this freezing fraction, although the Feo velocity, just $85 \%$ of the reference, gave a flatter leading region than the shapes formed at higher velocities. None of the shapes exactly reproduced the leading-edge features. The accumulation parameter, $A_{c}$, varied by about $\pm 7 \%$ from test to test, and the quantity of ice appeared to be insensitive to this variation.

$1 / 2$-Size Scaling at Nominal Freezing Fraction of 0.6 (fig. 4)

Figure 4 gives scaling results for constant velocity (fig. 4(a)), constant We (fig. 4(b)), average velocity (fig. 4(c)), and constant $\operatorname{Re}$ (fig. 4(d)). As with results discussed above, all were made with the water energy transfer parameter, $\phi$, held constant. A fifth scale test was made with the Re again matched, but with the air energy transfer parameter, $\theta$, instead of $\phi$, matched to the reference value (fig. 4(e)). The use of $\theta$ in place of $\phi$ results in a scale total temperature that is significantly reduced. Reference (1) noted that one of the practical problems of using constant-Re scaling is that the total temperature can be near or above freezing. Temperatures near freezing were found to produce scaled ice shapes that had little resemblance to reference shapes.

The relative sizes of the scaled shapes appear to be slightly larger than the reference, but that may have been because the scale accumulation parameter was as much as $9 \%$ higher than desired. Accretion limits are sometimes difficult to define precisely from traced ice shapes, but for the scale results of figure 4 , there appeared to be little effect of scale velocity on the accretion limit of the main ice shape. Scale velocity had a noticeable effect on the horn position, however.

Increasing scale velocity from $67 \mathrm{~m} / \mathrm{s}$ (constant velocity, fig. 4(a)) to $87 \mathrm{~m} / \mathrm{s}$ (constant $W e$, fig. 4(b)) produced only minor differences in the scale horn position. When the velocity was increased to $117 \mathrm{~m} / \mathrm{s}$ (average velocity, fig. 4(c)), the main scale horn angle and size conformed closely to the reference. The scale feathers also matched in size, although in the reference case, feathers were observed further aft than in the scale test.

The two constant-Re scaled tests (Figs. 4(d) and (e)), produced main ice shapes which approximately matched the reference size and shape in the horn region, but failed to simulate the size or extent of the feathers which formed aft of the main shape in the reference test. Reference (1) speculated that the high scale velocity which results when $R e$ is matched may strip small feathers from the surface early in their formation, thus preventing substantial feather growth from taking place. It is not evident from the results of figure 4 that there is any advantage in using scale velocities higher than the average of those obtained by applying constant $W e$ and constant $R e$.

There does not seem to be a significant difference between the scale shapes formed using either constant $\phi$ (fig. 4(d)) or constant $\theta$ (fig. 4(e)) when $R e$ is matched. This suggests that either of these parameters may be equally effective.

$1 / 2$-Size Scaling at Nominal Freezing Fraction of 0.5 (fig. 5)

The nominal freezing fraction for case 112 was 0.5 . The reference ice shape featured the horns typical of glaze 
ice with small feathers farther back on the airfoil. Figure 5 shows the five scaled ice shapes that resulted from testing with scale velocities ranging from those for the Feo method to the constant- $R e$ method. It can be seen from figure 5 that all scale velocities produced approximately the correct quantity of ice, and accretion limits appeared to be nearly the same as for the reference shape. However, as the scale velocity increased, the horns on the scaled shapes moved forward. The best match of the scaled and reference horn shape was obtained when the scale velocity was the average of the constant-We and constant-Re velocities. The horns for the constant-Re scaling projected forward of the reference horns.

The 1999 scale test results for the Feo, constant- $V$, constant- $W e$, and average- $V$ methods given in figure 5 were in close agreement with the 1998 results reported in reference 1. For the 1999 tests, the constant-Re conditions were found by matching $\theta$ since the constant $\phi$ approach, used in 1998, produced a scale total temperature slightly above freezing. The use of constant $\theta$ produced a scaled shape (fig. 5(e)) which, although not a perfect match, was more consistent with the reference shape than was the constant- $\phi$ scaled shape of 1998 . $^{1}$

The table of conditions below the plotted shapes indicates that the scaled tests had accumulation parameters as much as $9 \%$ higher than the reference and freezing fractions as much as $17 \%$ lower than the reference. These variations are greater than desired, so caution should be observed when forming conclusions.

2/3-Size Scaling at Nominal Freezing Fraction of 0.5 (fig. 6)

Scaling size to only $2 / 3$ the reference permits testing with constant $R e$ at more moderate scale velocities than are needed for $1 / 2$-scale testing. A series of tests were made scaling from $53.3-\mathrm{cm}$ to $35.6-\mathrm{cm}$ chord, using the same reference case as for the tests shown in figure 5 (case 112, with a nominal freezing fraction of 0.5 ). Five scale velocities were again tested, using the Feo, constant-velocity, constant- $W e$, average velocity and constant-Re methods. The constant-Re scaled conditions were determined with $\phi$ matched to the reference value.

The results are shown in figure 6. Because the scale size was closer to the reference, the differences between the scale and reference shapes are not as pronounced as those seen in figure 5. The relative quantity of ice and accretion limits for the scaled tests matched the reference for all scale velocities. However, the same effect of scale velocity on ice shape can be seen in both figures 5 and 6, with the scale horns moving forward as velocity increased. The best match of scale and reference ice shapes was again found for the average velocity method, and the scale horns were again somewhat too far forward when constant $R e$ was applied.

For the scale tests of figure 6 , the accumulation parameter varied from the reference by less than $2 \%$ and the freezing fraction by about $4 \%$. Because of the improved parameter matching over that in figure 5 , the figure 6 shape comparisons may have more credibility. In any case, the conclusions from the two figures are consistent: (1) The scale velocity has little effect on quantity of ice or accretion limits, and (2) the best match of scaled horn size and position was obtained when the scale velocity was chosen as the average of the constant- $W e$ and the constant-Re velocities.

\section{Concluding Remarks}

Scaling tests were performed in the NASA Glenn Icing Research Tunnel using a 53.3-cm-chord NACA 0012 model for reference tests with 35.6- and 26.7-cm-chord scale models. Scale test conditions were found using the Ruff scaling method for sea-level tunnels along with five methods to select scale velocity. Four of these methods were based on insuring that some physically based parameter had the same value for both scale and reference conditions. The first method matched the Feo water film thickness, the second, the test-section velocity, the third, the Weber number, the fourth, the Reynolds number. The fifth method averaged the velocities found by matching the Weber number and by matching the Reynolds number. These methods gave scale velocities that ranged from about $85 \%$ of the reference to about $220 \%$ for $1 / 2$-scale testing and from $90 \%$ to $155 \%$ for the $2 / 3$-scale tests. For some tests the effect of matching the air-energy transport parameter, $\theta$, instead of the water-energy transport parameter, $\phi$, was evaluated.

The observations and conclusions from this study are:

1. Limited testing showed no effect of whether constant $\phi$ or constant $\theta$ was used in the scaling equations. Constant $\phi$ uses simpler calculation routines, but constant $\theta$ gives a lower scale total temperature when the scale velocity is higher than the reference.

2. The quantity of ice was adequately simulated by any of the scale velocities tested. Accretion limits were difficult to define precisely, but appeared to be approximately simulated using all of the scale velocities considered. 
3. For a freezing fraction of about 0.8 , there appeared to be no effect of scale velocity on scale ice shape. This observation is consistent with the results of reference (1).

4. For nominal freezing fractions of 0.6 and 0.5 , the scale horns moved forward as scale velocity increased. The best scaling resulted from averaging the constant- $W e$ and the constant- $R e$ scale velocities. For a freezing fraction of 0.5 , the constant-Re method produced ice shapes whose horns projected forward beyond those of the reference shape.

One-half-scale tests with nominal freezing fractions of 0.6 and 0.5 and two-thirds-scale tests with a nominal freezing fraction of 0.5 all indicated that averagevelocity scaling gave the best simulation of the reference ice shape. This method of choosing the scale velocity has no physical basis, but its success could possibly indicate that both $W e$ and $R e$ play nearly equally important roles in the physics of ice accretion. Thus, while these two parameters cannot be simultaneously matched using a practical scaling method, the average-velocity approach may provide an acceptable compromise. It is also possible that some other physical parameter is coincidentally satisfied, at least approximately, by the constant-velocity method. In any case, before final conclusions can be reached, tests with additional reference conditions and different scaling ratios are needed to confirm the observations reported here.

\section{$\underline{\text { References }}$}

${ }^{1}$ Anderson, David N. and Ruff, Gary A., "Evaluation of Methods to Select Scale Velocities in Icing Scaling Tests," AIAA-99-0244, January 1999.

${ }^{2}$ Charpin, Francois and Fasso, Guy, "Icing Testing in the Large Modane Wind Tunnel on Full Scale and Reduced Scale Models," L'Aeronautique et l'Astronautique, no. 38, 1972. English translation published as NASA TM-75373, March 1979.

${ }^{3}$ Ruff, G.A.: "Analysis and Verification of the Icing Scaling Equations," AEDC-TR-85-30, Vol. 1 (Rev), March 1986.

4 Bilanin, A.J., "Proposed Modifications to the Ice Accretion/Icing Scaling Theory," AIAA Paper AIAA88-0203, January 1988.

5 Langmuir, Irving and Blodgett, Katharine B.: "A Mathematical Investigation of Water Droplet Trajectories," Army Air Forces Technical Report No. 5418, February 1946.
6 Messinger, B.L., "Equilibrium Temperature of an Unheated Icing Surface as a Function of Airspeed," J. Aeron. Sci. vol. 20 no. 1, January 1953, pp. 29-42.

${ }^{7}$ Tribus, Myron, Young, G.B.W. and Boelter, L.M.K., "Analysis of Heat Transfer Over a Small Cylinder in Icing Conditions on Mount Washington," Trans. ASME vol. 70, November 1948, pp. 971-976.

${ }^{8}$ Kind, R.J., Dillon, T., Gaydos, J.A. and Oleskiw, M., "Evidence for the Importance of Scaling Viscous Effects in the Water Film in Glaze Icing Tests," AIAA98-0196, January 1998.

${ }^{9}$ Feo, A. and Urdiales, M., "Stagnation Point Probe in a Water Spray Immersed in an Airstream," $\phi A E / T N O / 0452 / 003 / I N T A / 95$, Instituto Nacional de Técnica Aeroespacial, February 1995.

10 Bilanin, Alan J. and Anderson, David N.: "Ice Accretion with Varying Surface Tension," AIAA-950538 and NASA TM-106826, January 1995.

${ }^{11}$ Anderson, David N., "Evaluation of Constant-WeberNumber Scaling for Icing Tests," AIAA-96-0636 and NASA TM-107141, January 1996.

12 Soeder, Ronald H., Sheldon, David W., Andracchio, Charles R., Ide, Robert F., Spera, David A. and Lalli, Nick M., "NASA Lewis Icing Research Tunnel User Manual," NASA TM-107159, June 1996.

${ }^{13}$ Irvine, Thomas B., Oldenburg, John R. and Sheldon, David W., "New Icing Cloud Simulation System at the NASA Glenn Research Center Icing Research Tunnel," NASA/TM-1999-208891, June 1999 and AIAA-980143, January 1998.

${ }^{14}$ Ide, Robert F., "Operating Envelopes and Calculation Procedure for Spray Settings for the NASA-Lewis Icing Research Tunnel," unpublished NASA Lewis document, November 1998. 


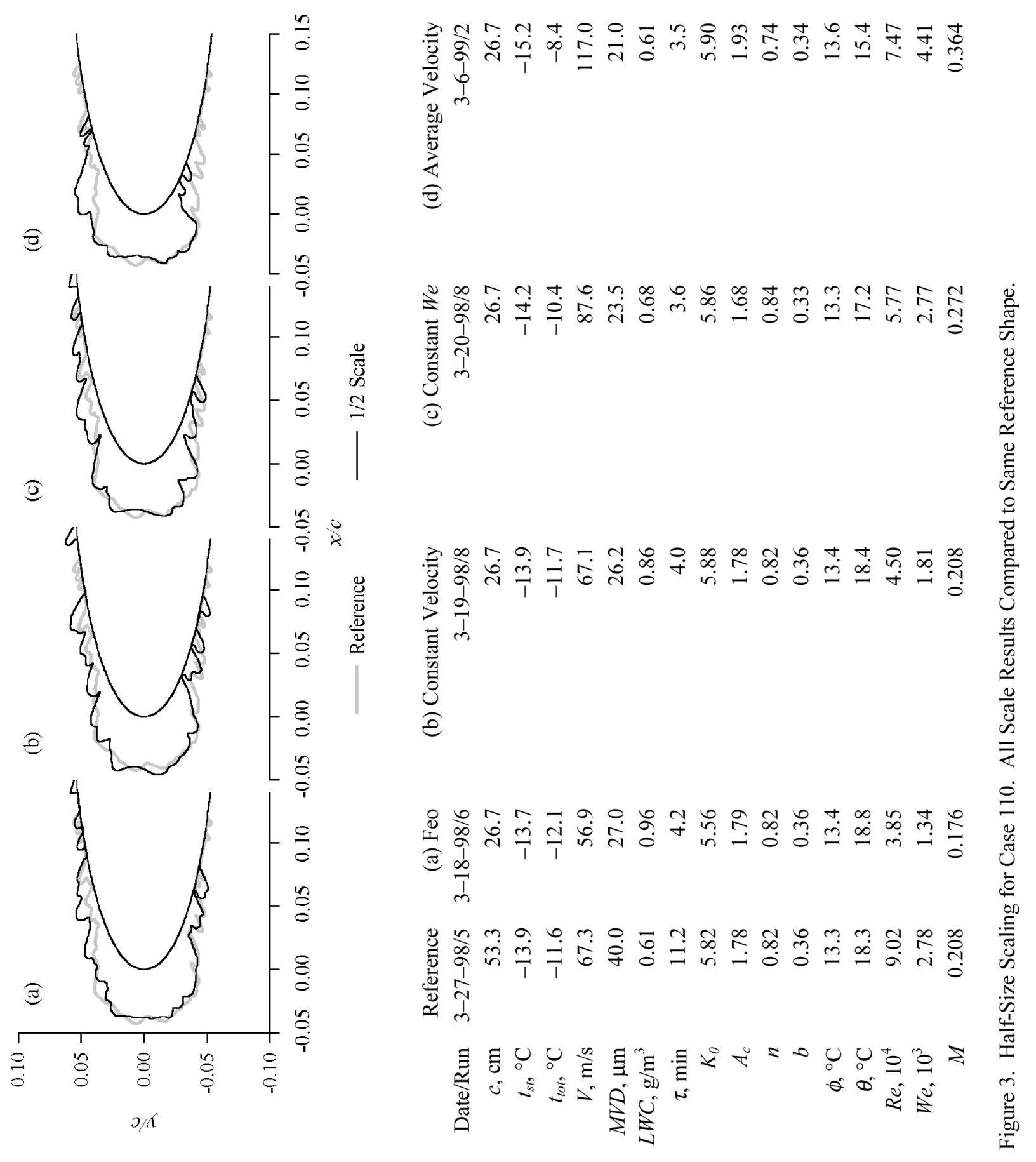



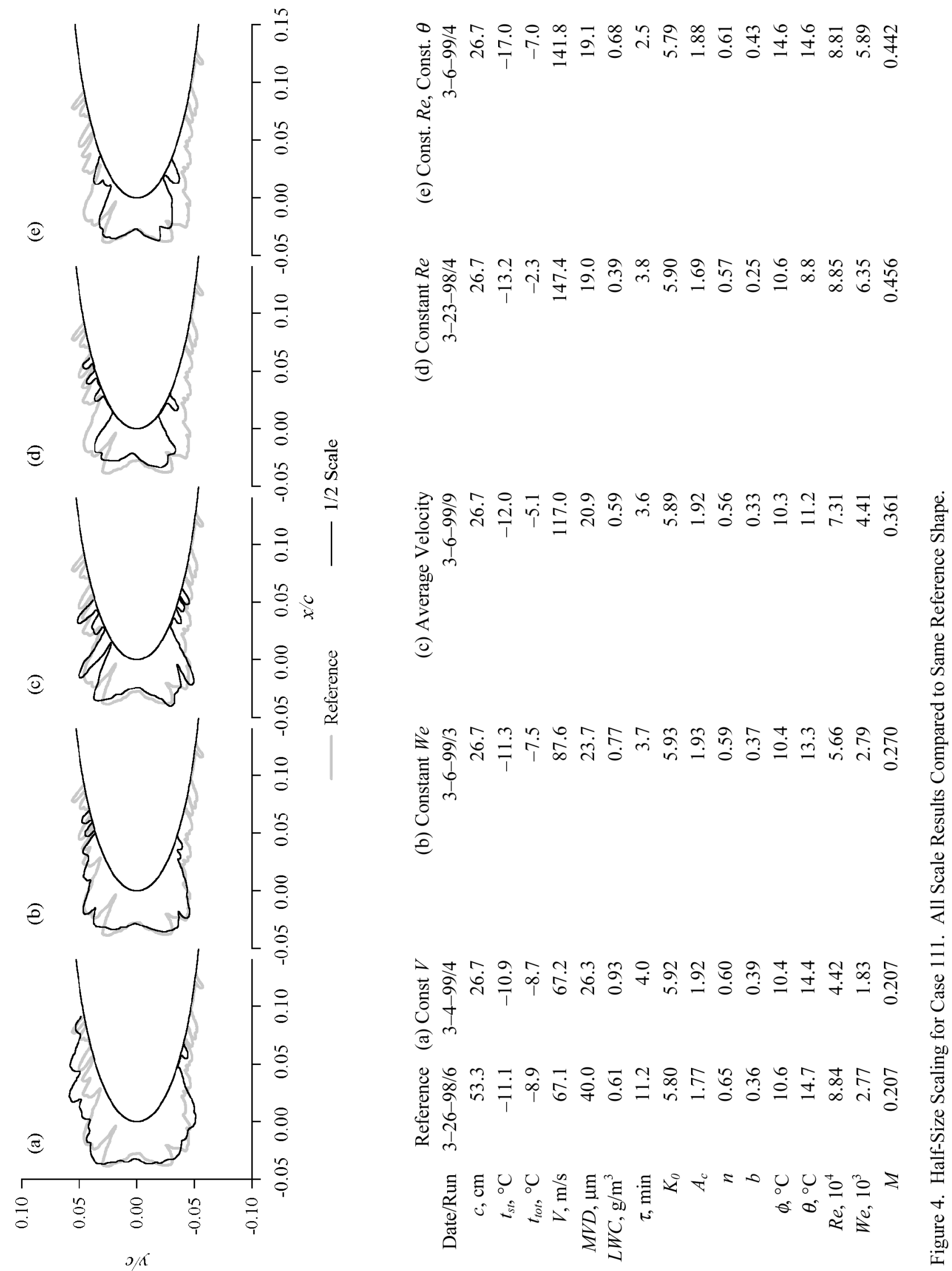

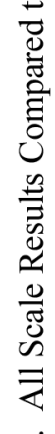

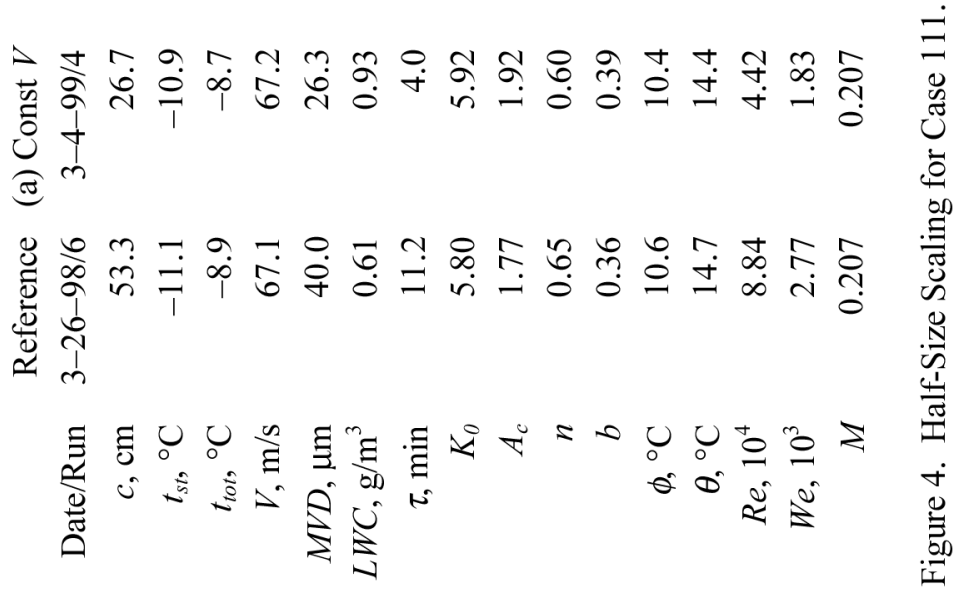




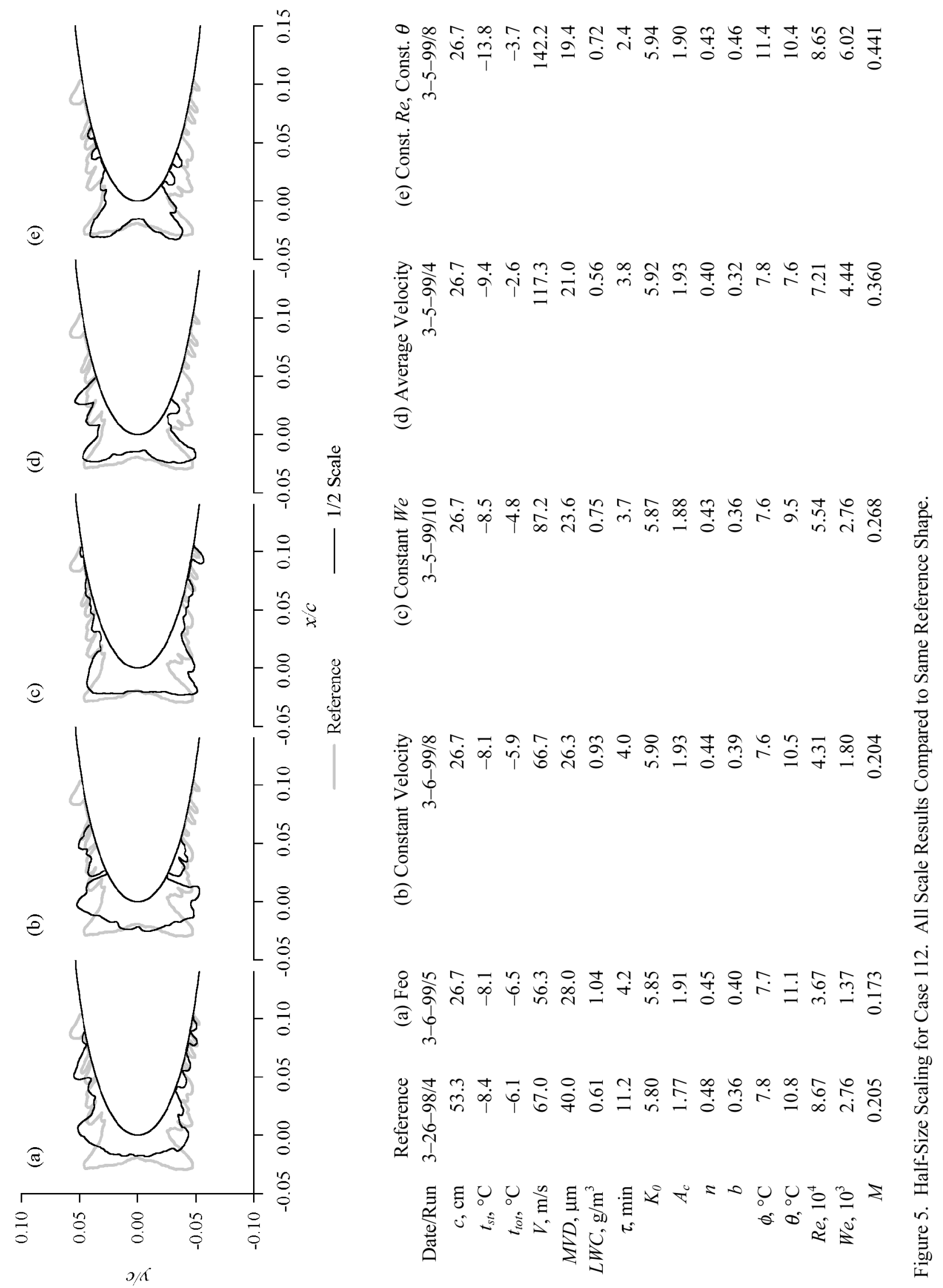



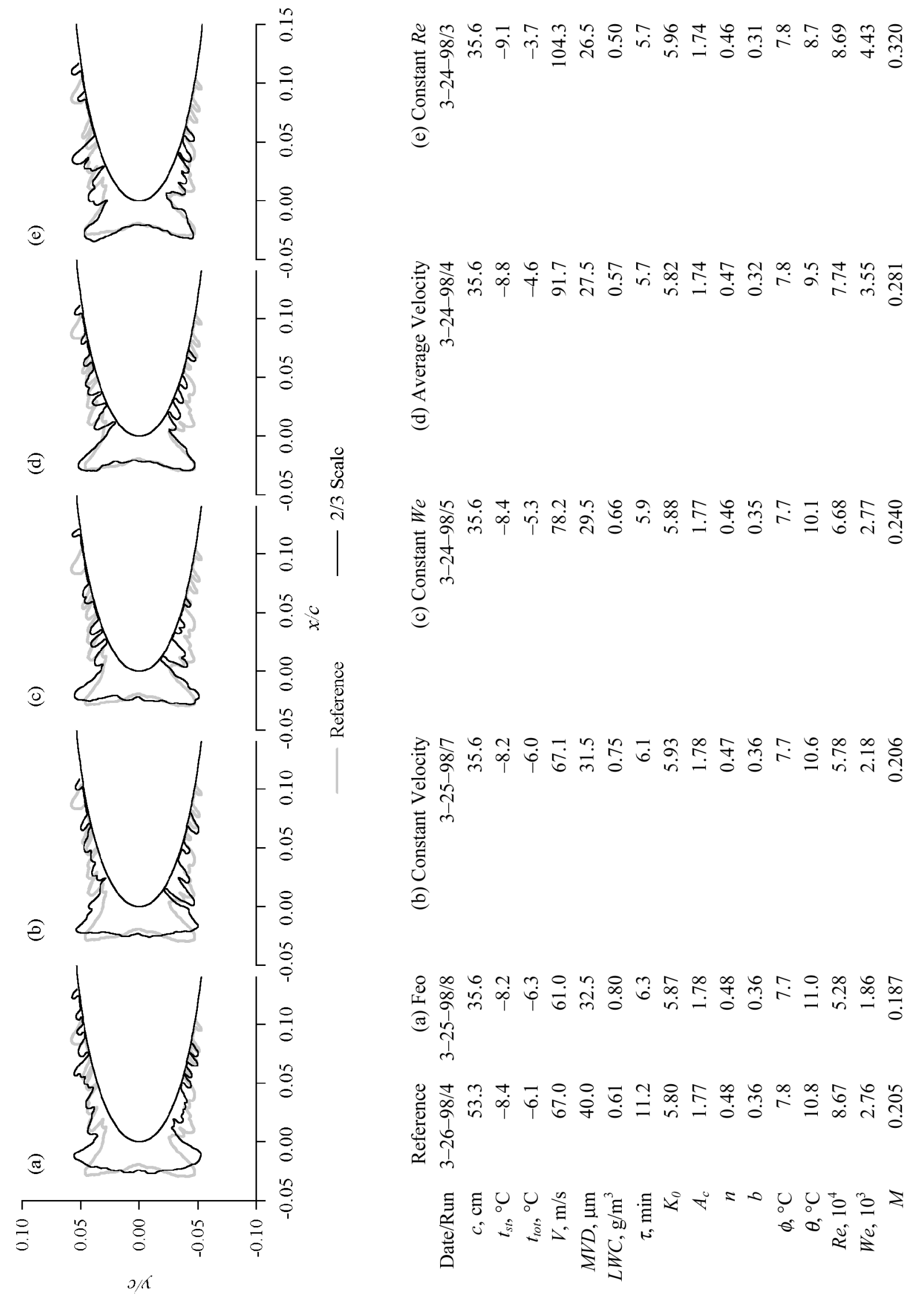

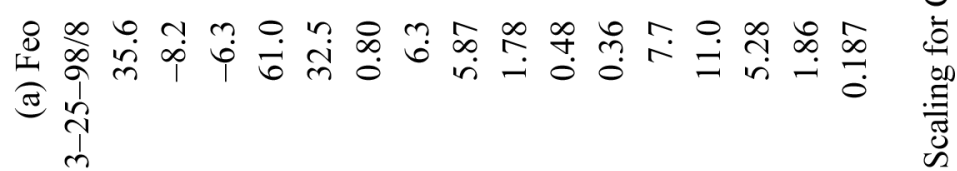

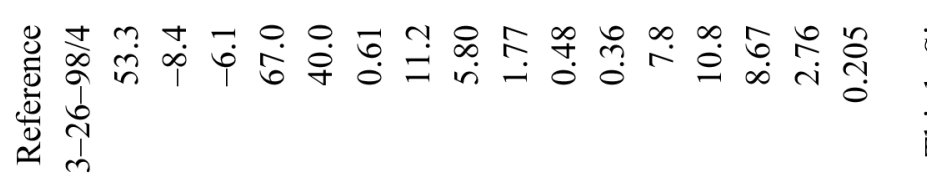

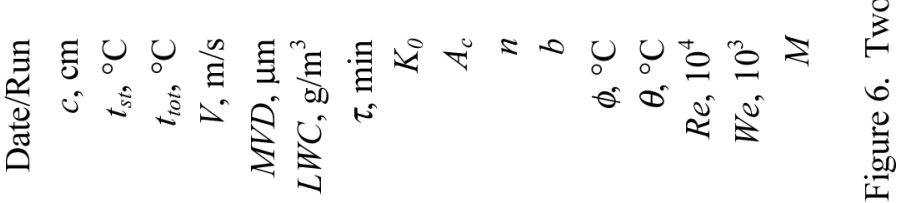




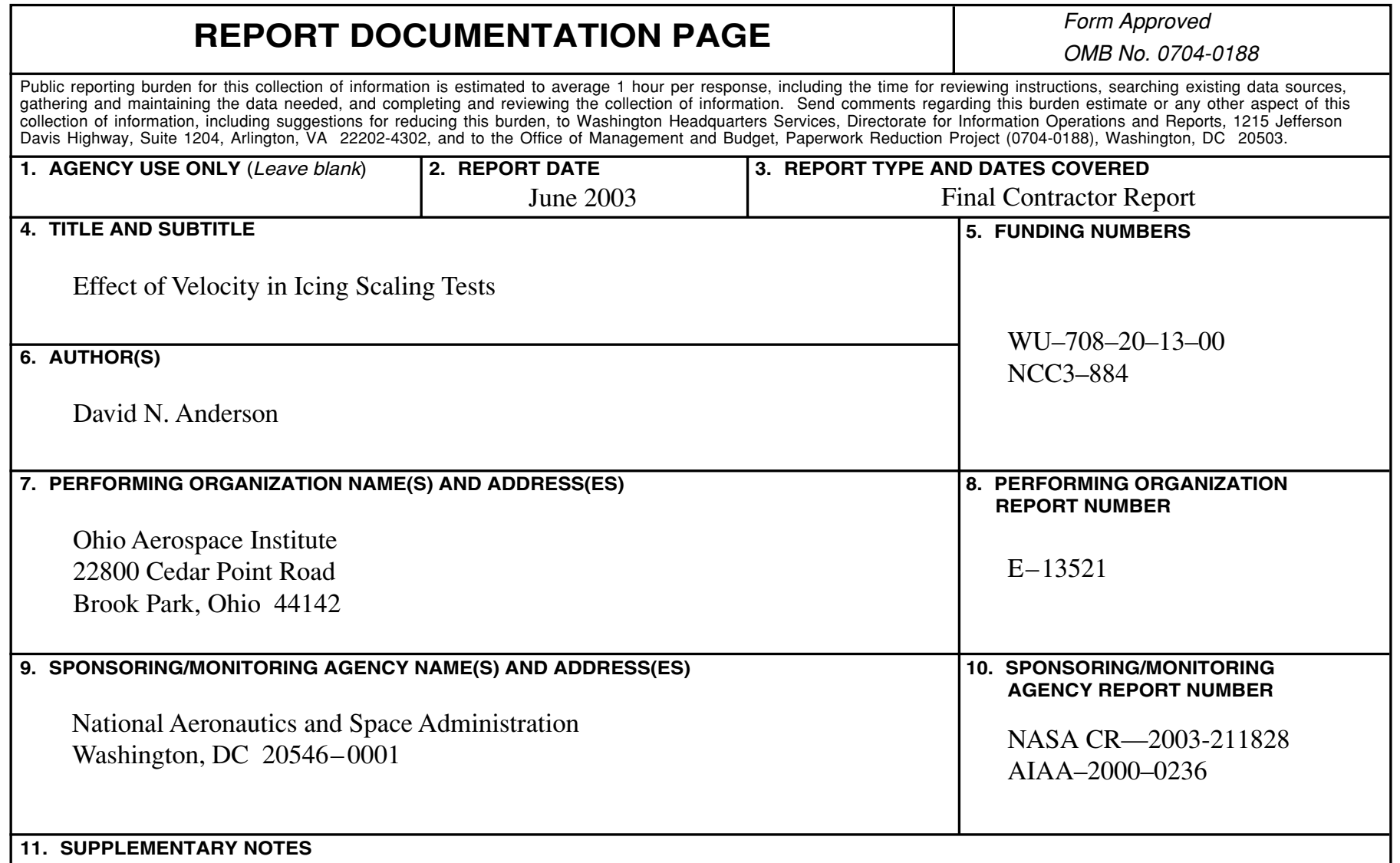

Prepared for the 38th Aerospace Sciences Meeting and Exhibit sponsored by the American Institute of Aeronautics and Astronautics, Reno, Nevada, January 10-13, 2000. Project Manager, Thomas H. Bond, Turbomachinery and Propulsion Systems Division, NASA Glenn Research Center, organization code 5840, 216-433-3900.

12a. DISTRIBUTION/AVAILABILITY STATEMENT

12b. DISTRIBUTION CODE

Unclassified - Unlimited

Subject Category: 02

Distribution: Nonstandard

Available electronically at http://gltrs.grc.nasa.gov

This publication is available from the NASA Center for AeroSpace Information, 301-621-0390.

13. ABSTRACT (Maximum 200 words)

This paper presents additional results of a study first published in 1999 to determine the effect of scale velocity on scaled icing test results. Reference tests were made with a 53.3-cm-chord NACA 0012 airfoil model in the NASA Glenn Icing Research Tunnel at an airspeed of $67 \mathrm{~m} / \mathrm{s}$, an $M V D$ of $40 \mu \mathrm{m}$, and an $L W C$ of $0.6 \mathrm{~g} / \mathrm{m}^{3}$. Temperature was varied to provide nominal freezing fractions of $0.8,0.6$, and 0.5 . Scale tests used both 35.6- and 27.7-cm-chord 0012 models for $2 / 3$ - and 1/2-size scaling. Scale test conditions were found using the modified Ruff (AEDC) scaling method with the scale velocity determined in five ways. Four of the scale velocities were found by matching the scale and reference values of water-film thickness, velocity, Weber number, and Reynolds number. The fifth scale velocity was simply the average of those found by matching the Weber and Reynolds numbers. The resulting scale velocities ranged from 85 to 220 percent of the reference velocity. For a freezing fraction of 0.8 , the value of the scale velocity had no effect on how well the scale ice shape simulated the reference shape. For nominal freezing fractions of 0.5 and 0.6 , the best simulation of the reference shape was achieved when the scale velocity was the average of the constant-Weber-number and the constant-Reynoldsnumber velocities.

\section{SUBJECT TERMS}

Aircraft safety; Aircraft icing; Icing scaling

\begin{tabular}{|c|c|c|c|}
\hline $\begin{array}{c}\text { 17. SECURITY CLASSIFICATION } \\
\text { OF REPORT } \\
\text { Unclassified }\end{array}$ & $\begin{array}{c}\text { 18. SECURITY CLASSIFICATION } \\
\text { OF THIS PAGE } \\
\text { Unclassified }\end{array}$ & $\begin{array}{c}\text { 19. SECURITY CLASSIFICATION } \\
\text { OF ABSTRACT } \\
\text { Unclassified }\end{array}$ \\
\hline
\end{tabular}

NSN 7540-01-280-5500 